\section{( OPEN ACCESS}

\title{
Apolipoprotein E $\varepsilon 2$ genotype delays onset of dementia with Lewy bodies in a Norwegian cohort
}

\author{
Guro Berge, ${ }^{1}$ Sigrid B Sando, ${ }^{1,2}$ Arvid Rongve, ${ }^{3}$ Dag Aarsland, ${ }^{4,5,6}$ Linda R White ${ }^{1,2}$
}

\begin{abstract}
${ }^{1}$ Faculty of Medicine,
Department of Neuroscience, Norwegian University of Science and Technology (NTNU), Trondheim, Norway ${ }^{2}$ Department of Neurology, University Hospital of Trondheim, Trondheim, Norway ${ }^{3}$ Department of Psychiatry, Haugesund Hospital, Haugesund, Norway ${ }^{4}$ Department of Neurobiology, Care Sciences, and Society, Alzheimer's Disease Research Center, Karolinska Institute, Stockholm, Sweden ${ }^{5}$ Department of Psychiatry, Akershus University Hospital, Norway

${ }^{6}$ Centre for Age-Related Medicine, Stavanger University Hospital, Stavanger, Norway
\end{abstract}

\section{Correspondence to} Professor Linda Rosemary White, Department of Neuroscience, Faculty of Medicine, Norwegian University of Science and Technology, Trondheim, N0-7491, Norway; linda.white@ntnu.no

Received 13 November 2013 Revised 17 January 2014 Accepted 10 February 2014 Published Online First 17 March 2014

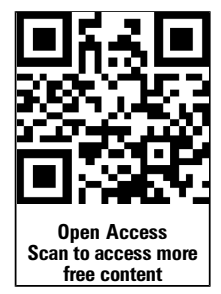

\section{ABSTRACT \\ Background Results conflict concerning the relevance of $A P O E$ alleles on the development of dementia with Lewy bodies (DLB), though they are well established in connection with Alzheimer's disease (AD). The role of $A P O E$ alleles in a Norwegian cohort of patients with DLB was therefore examined compared with patients with $A D$ and healthy control individuals.}

Methods The study included 156 patients with DLB diagnosed according to the consensus criteria guidelines, 519 patients diagnosed with $A D$ according to the National Institute of Neurological and Communicative Diseases and Stroke/Alzheimer's Disease and Related Disorders Association (NINCDS/ARDRA) criteria and 643 healthy elderly volunteers. Patients were recruited through hospitals, outpatient clinics, nursing homes or from local care authorities in central and south-western parts of Norway. Healthy individuals were recruited from caregivers and societies for retired people.

Results Subjects carrying an $A P O E \varepsilon 2$ allele had a reduced risk for developing DLB (OR $0.4, \mathrm{CI} 0.3$ to 0.8 , $p=0.004$ ), and the onset of disease was delayed by 4 years ( $p=0.01$, Mann-Whitney U test). Conversely, the APOE $\varepsilon 4$ allele increased the risk for development of DLB (OR 5.9, Cl 2.7 to $13.0, p<0.0005$ for homozygotes). Similar results were found for patients with $A D$ regarding the effect of APOE $\varepsilon 2$, though the protective effect appeared to be slightly less pronounced than in DLB. This study is one of the largest regarding DLB and $A P O E$ to date.

Conclusion The results indicate that $A P O E \varepsilon 2$, a protective factor in $A D$, has a clear beneficial effect on the development of DLB also.

\section{INTRODUCTION}

Several neurodegenerative diseases may arise as a consequence of sequential biochemical processes operating in more than one disease entity, ${ }^{1}$ and could represent points on a continuum of neuropathological change, rather than being distinct nosological entities. ${ }^{2}$ The human APOE gene has undergone extensive study in connection with neurodegenerative disease since the APOE $\varepsilon 4$ allele was found to be the most important genetic risk factor for late-onset Alzheimer's disease (AD), ${ }^{3} 4$ including a large Norwegian cohort, ${ }^{5}$ as well as early-onset AD. ${ }^{6}$ Conversely, the $A P O E \varepsilon 2$ isoform has been found in some studies to impart a reduced risk of AD. ${ }^{7-9}$

Dementia occurring before or during the first year of Parkinsonism is classified as dementia with Lewy bodies (DLB), with core features including visual hallucinations and fluctuating cognition. ${ }^{10} \mathrm{It}$ is the second most common neurodegenerative dementia type after $\mathrm{AD}$ among older patients. ${ }^{11}$
There is overlap between the neuropathology of DLB and AD, and most DLB patients have at least some degree of plaque pathology and even tangle pathology. Risk factors for AD could therefore in theory also increase the risk of DLB. ${ }^{11} 12$ Previous studies have suggested the APOE $\varepsilon 4$ allele to be a risk factor for DLB, ${ }^{13-16}$ though not all. ${ }^{7}$

Norway is a suitable country for conducting genetic analysis of neurological disease, as the ethnic population has remained relatively stable for several centuries and is comparatively homogeneous. The present study is one of the largest to date concerning the $A P O E$ genotype in connection with DLB, and tested the hypothesis that $A P O E$ genotype affects the risk for developing DLB. The results have been compared with a population of patients with $\mathrm{AD}$, as well as with elderly control individuals without signs of any neurodegenerative disease.

\section{METHODS}

Subjects

The clinical material (table 1) consisted of a total of 1318 individuals: 156 patients diagnosed with DLB, 519 patients diagnosed with $\mathrm{AD}$ and 643 elderly control individuals, all ethnic Norwegians. Participants from central and western parts of Norway were included in one of two long-term ongoing studies of dementia (TrønderBrain or DemVest).

Caregivers not genetically related to the patients, as well as other elderly volunteers recruited from societies for retired people in central Norway, all without first-degree relatives with dementia, were enrolled as controls in the TrønderBrain study as described earlier. ${ }^{5}$ They were healthy for their age and displayed no signs of a neurological disorder. They were age- and sex-matched to the patient groups as closely as possible.

Patients in the TrønderBrain study were recruited through the University Hospital of Trondheim, the district hospital in Namsos, nursing homes and local care authorities in central Norway. Patients with $\mathrm{AD}$ (diagnosed according to the National Institute of Neurological and Communicative Diseases and Stroke/Alzheimer's Disease and Related Disorders Association (NINCDS-ADRDA) criteria $^{17}$ as described elsewhere ${ }^{5}$ ) or DLB were diagnosed by a single neurologist (SBS).

The TrønderBrain DLB patients and/or a suitable proxy gave a case history, including occurrence of core features of DLB. The neurological examination included Mini Mental State Examination (MMSE), Clock Drawing Test and the motor examination part of Unified Parkinson's Disease Rating Scale 
Table 1 Demographic data for the study groups

\begin{tabular}{llllll}
\hline & DLB (total) & DLB (TrønderBrain) & DLB (DemVest) & AD (TrønderBrain) & Healthy controls (TrønderBrain) \\
\hline Cases (total) & 156 & 103 & 53 & 519 & 643 \\
Probable/possible DLB & $135 / 21$ & $88 / 15$ & $47 / 6$ & & \\
Females (\%) & $67(42.9)^{*}+$ & $44(42.7)$ & $23(43.4)$ & $351(67.6)^{*}$ & $388(60.3)$ \\
Age at onset (y) & $72.3 \pm 7.9$ & $72.3 \pm 7.7$ & $72.1 \pm 8.3$ & $71.3 \pm 9.3$ & $\mathrm{NA}$ \\
Age at inclusion (y) & $76.3 \pm 7.6^{*}$ & $76.9 \pm 7.7$ & $75.3 \pm 7.4$ & $76.0 \pm 9.9^{*}$ & $74.8 \pm 7.2$ \\
Duration (y) & $4.2 \pm 3.0 \dagger$ & $4.5 \pm 3.1$ & $3.5 \pm 2.5$ & $4.7 \pm 3.2$ & $\mathrm{NA}$ \\
Range of onset (y) & $46-89$ & $46-88$ & $50-89$ & $47-88$ & $\mathrm{NA}$ \\
Mean education (y) & $9.8 \pm 3.1$ & $9.9 \pm 3.1$ & $9.6 \pm 3.0$ & $9.5 \pm 3.1^{*}$ & $9.8 \pm 2.9$ \\
MMSE & $19.6 \pm 7.5$ & $17.9 \pm 8.4 \ddagger$ & $22.9 \pm 3.3$ & $17.8 \pm 8.1 \dagger$ & $\mathrm{NA}$ \\
UPDRS III & $16.9 \pm 12.9 \dagger$ & $18.7 \pm 12.3 \ddagger$ & $13.9 \pm 13.6$ & $3.3 \pm 6.0(\mathrm{n}=294)$ & $\mathrm{NA}$ \\
\hline
\end{tabular}

Statistical analysis was initially made using the Kruskal-Wallis test for multiple groups. Where values of $p<0.05$ were found, subsequent individual group comparisons were made with the Mann-Whitney U test.

All $p$ values $\leq 0.03$.

*Significant difference between a patient group and the control group.

tSignificant difference between the groups of patients with DLB or AD.

¥Significant difference between the two DLB cohorts.

AD, Alzheimer's disease; DLB, dementia with Lewy bodies; MMSE, Mini Mental State Examination; UPDRS, Unified Parkinson's Disease Rating Scale.

(UPDRS). Diagnosis of probable or possible DLB was based on the original consensus criteria guidelines, ${ }^{18}$ but for the purposes of analysis were considered as a single group. About $20 \%$ of the TrønderBrain cases with clinically diagnosed DLB had a dopamine-transporter SPECT ( ${ }^{123}$ I-Ioflupane) to support the diagnosis. Pathological confirmation of the clinical dementia diagnosis was available for two patients with DLB.

Patients included in the multicentre DemVest study were recruited from outpatient clinics in the counties of Hordaland and Rogaland. DLB patients with mild dementia $(n=53)$ were examined by a licensed specialist in geriatrics or psychiatry, and diagnosis was made after discussion by a consensus panel, and according to the new criteria. ${ }^{19}$ Each patient was interviewed at inclusion, usually with a caregiver attending who could provide supplementary information. Medical history, neurological and neuropsychological examinations were performed. All patients were assessed for diagnostically relevant information, including the motor examination part of UPDRS, the Neuropsychiatric Inventory. The Mayo fluctuating cognition scale and Mayo sleep scale were administered to assess visual hallucinations, fluctuating cognition and REM-sleep behavioural disorder. Supplemental investigations included routine blood tests, brain MRI or CT, as well as cerebrospinal fluid assessment in some of the cases. Overall, 28\% of the DemVest cases had a dopamine-transporter SPECT ( ${ }^{123}$ I-Ioflupane) to support the diagnosis, and pathological confirmation of the clinical dementia diagnosis was available for the first seven cases from the DemVest material.

\section{APOE genotyping}

APOE genotyping was performed on blood samples from all patients and control individuals. Fresh whole blood was drawn into $6 \mathrm{~mL}$ EDTA-vacutainers, and DNA isolated using the QIAamp DNA Blood Mini Kit (QIAGEN), together with the spin protocol provided. Random samples of isolated DNA were checked for purity using NanoDrop technology, and all samples were frozen and stored at $-80^{\circ} \mathrm{C}$. APOE analysis was either performed according to the protocol described elsewhere ${ }^{5}$ or using the Fast Start DNA Master HybProbe Kit (Roche) in combination with the LightMix ApoE C112R R158C kit from TiB MolBiol (Berlin, Germany) according to the manufacturer's instructions, followed by APOE genotyping with LightCycler technology (Roche).

\section{Statistical analyses}

No difference in the frequency of $A P O E$ alleles was found between the two DLB cohorts, and the genotype data were therefore pooled. Statistical analyses were performed using SPSS V.21.0. Categorical variables were compared using Pearson's $\chi^{2}$ test. The Kruskal-Wallis test (KW) was used for comparisons between multiple groups, followed by the Mann-Whitney U test (MW) between individual groups. OR were calculated for APOE alleles by binary logistic regression, using the $A P O E \varepsilon 3 / \varepsilon 3$ genotype as reference value, both unadjusted and adjusting for potential confounders (age and gender). Two-sided $\mathrm{p}$ values $<0.05$ were considered significant. Where applicable, the mean $\pm \mathrm{SD}$ is given.

\section{Ethical considerations}

Written, informed consent was obtained from all patients or suitable proxies, and from all control individuals. The biobanks are licensed by the Norwegian Directorate for Social and Health Affairs, and the research project was approved by the relevant Regional Committee for Medical Research Ethics.

\section{RESULTS}

The demographic data are shown in table 1. Significant differences were found in gender between the test groups, with more men among patients with DLB compared with both $\mathrm{AD}$ and control groups $(\mathrm{p}<0.0005, \mathrm{KW})$, but more females among patients with $\mathrm{AD}$ compared with controls $(\mathrm{p}=0.01, \mathrm{MW})$ as is typically found. ${ }^{20}$ Mean education was significantly lower in the group with $\mathrm{AD}$ compared with the controls ( $\mathrm{p}=0.002, \mathrm{MW})$, though only by a few months. Regarding age at inclusion, no significant difference was found between the patient groups, but both were significantly older than controls $(\mathrm{p}<0.0005, \mathrm{KW})$, though by less than 2 years. No significant difference was found between the DLB and AD groups for age at onset of disease, but patients with DLB had a significantly shorter duration of disease at inclusion compared with those with $\mathrm{AD}(\mathrm{p}=0.03, \mathrm{MW})$. UPDRS scores were significantly increased in patients with DLB compared with those with $\mathrm{AD}(\mathrm{p}<0.0005, \mathrm{MW})$. The latter group had significantly lower scores on the MMSE $(p=0.015$, $\mathrm{MW}$ ). Consistent with selecting only patients with mild DLB, the DemVest DLB patients had less cognitive $(p=0.001, M W)$ and motor impairment $(\mathrm{p}=0.017, \mathrm{MW})$ than the TrønderBrain DLB patients. In the cohort of patients with DLB, $87.2 \%$ of the 
Table 2 APOE allele and genotype frequency in patients with DLB or AD, and healthy control individuals

\begin{tabular}{|c|c|c|c|c|c|c|c|c|c|c|}
\hline \multirow[b]{2}{*}{ Group } & \multirow[b]{2}{*}{$\mathrm{n}$} & \multicolumn{3}{|c|}{ Allele frequency (\%) } & \multicolumn{6}{|c|}{ Genotypes (\%) } \\
\hline & & $\varepsilon 2$ & $\varepsilon 3$ & $\varepsilon 4$ & $\varepsilon 2 / \varepsilon 2$ & $\varepsilon 2 / \varepsilon 3$ & $\varepsilon 2 / \varepsilon 4$ & $\varepsilon 3 / \varepsilon 3$ & $\varepsilon 3 / \varepsilon 4$ & $\varepsilon 4 / \varepsilon 4$ \\
\hline DLB & 156 & 5.1 & 62.8 & 32.1 & 0.6 & 4.5 & 4.5 & 41.0 & 40.4 & 9.0 \\
\hline $\mathrm{F}$ & 67 & 7.5 & 57.5 & 35.0 & 1.5 & 7.5 & 4.5 & 34.3 & 38.8 & 13.4 \\
\hline M & 89 & 3.4 & 66.8 & 29.8 & 0.0 & 2.2 & 4.5 & 46.1 & 41.6 & 5.6 \\
\hline AD & 519 & 5.8 & 51.3 & 42.9 & 0.2 & 6.2 & 5.0 & 27.2 & 42.2 & 19.3 \\
\hline $\mathrm{F}$ & 351 & 5.7 & 51.7 & 42.6 & 0.3 & 5.1 & 5.7 & 28.2 & 41.9 & 18.8 \\
\hline M & 168 & 6.0 & 50.6 & 43.4 & 0.0 & 8.3 & 3.6 & 25.0 & 42.9 & 20.2 \\
\hline Healthy controls & 643 & 10.6 & 75.0 & 14.4 & 0.6 & 16.3 & 3.6 & 56.8 & 20.4 & 2.3 \\
\hline $\mathrm{F}$ & 388 & 10.2 & 75.5 & 14.3 & 0.5 & 15.7 & 3.6 & 57.2 & 20.9 & 2.1 \\
\hline M & 255 & 11.2 & 74.3 & 14.5 & 0.8 & 17.3 & 3.5 & 56.1 & 19.6 & 2.7 \\
\hline
\end{tabular}

No significant difference in $A P O E$ allele and genotype frequencies between the TrønderBrain and DemVest cohorts, so all DLB patients have been pooled to a single group.

The APOE \&4 allele was significantly increased in both the DLB $(p<0.0005)$ and AD patient groups $(p<0.0005)$ compared with healthy controls, and was more common in $A D$ than $D L B$ $(p=0.004)$. Conversely, the APOE $\varepsilon 2$ allele was reduced in the DLB $(p=0.002)$ and $A D(p<0.0005)$ patient groups compared with controls $\left(P e a r s o n ' s \chi^{2}\right.$ test).

$A D$, Alzheimer's disease DLB, dementia with Lewy bodies.

SPECT analyses supported the clinical diagnosis. No SPECT results were available for AD or healthy controls. The percentage of scans not supporting the clinical diagnosis of DLB $(12.8 \%)$ is similar to recently published data. ${ }^{21}$

$A P O E$ allele and genotype frequency with $\mathrm{p}$ values are shown in table 2. Although the frequency of the APOE $\varepsilon 4$ allele was significantly increased in both patients with DLB and AD, it was less frequent in the group with DLB compared with AD (32\% in $\mathrm{DLB}, 43 \%$ in $\mathrm{AD}$, against $14 \%$ in controls). Conversely, the highest frequency of the APOE $\varepsilon 2$ allele was found in the control group (10.6\%) compared with both patient groups (DLB and AD between 5\% and 6\%), though no significant difference between the patient groups was found. In the overall cohort of patients with DLB, $10 \%$ were homozygous or heterozygous for $A P O E \varepsilon 2$. In those patients given a dopaminetransporter SPECT, the number carrying APOE $\varepsilon 2$ was $9 \%$. The allele frequencies for men and women did not differ significantly either in controls or patients.

The OR for developing DLB or AD were calculated for $A P O E \varepsilon 2$ and $\varepsilon 4$, with respectively zero alleles as the reference value, as shown in table 3 . Due to the low number of homozygotic $A P O E \& 2$ carriers, OR values were only calculated for bearers of one or two alleles combined. The APOE $\varepsilon 2$ allele

Table 3 OR for developing DLB or $A D$ relative to $A P O E \varepsilon 2$ and APOE\&4 alleles

\begin{tabular}{lll}
\hline & DLB vs CTR & AD vs CTR \\
\hline $\begin{array}{l}\text { No. of } A P O E \text { alleles } \\
1 \text { or } 2 \text { APOE \&2 alleles }\end{array}$ & & \\
OR & 0.4 & 0.5 \\
Cl & 0.2 to 0.7 & 0.4 to 0.7 \\
p Value & 0.002 & $<0.0005$ \\
1 APOE $\varepsilon 4$ allele & & \\
OR & 3.0 & 4.3 \\
Cl & 2.1 to 4.3 & 3.3 to 5.7 \\
p Value & $<0.0005$ & $<0.0005$ \\
2 APOE $\varepsilon 4$ alleles & & \\
OR & 6.0 & 19.3 \\
Cl & 2.8 to 13.1 & 10.8 to 34.2 \\
p Value & $<0.0005$ & $<0.0005$ \\
\hline
\end{tabular}

$A D$, Alzheimer's disease; CTR, healthy controls; DLB, dementia with Lewy bodies. significantly reduced the risk of developing either DLB or AD. In the case of $A P O E \varepsilon 4$, an allele-dose dependent relationship was found for increasing the risk of DLB, though not as strongly as the increased risk for AD.

When these results were corrected for age and gender, the reduced risk of developing DLB or AD in carriers of the APOE ع2 allele was maintained, as shown in table 4. Similarly, an increased risk was still found for developing DLB or AD in carriers of the $A P O E \varepsilon 4$ allele after correction.

The effect of the APOE $\varepsilon 2$ allele on age at onset with $\mathrm{p}$ values in patients with DLB and patients with $A D$ is shown in table 5. For the patients with DLB, carriers of APOE $\varepsilon 2$ developed the disease on average 4 years later than those without the allele. Patients with AD carrying APOE $\varepsilon 2$ developed the disease on average around 3 years later than those without the allele. Both these results were significant. Regarding the APOE $\varepsilon 4$ allele, only a weak trend towards a reduction in age at onset was found in patients with DLB. For the patients with AD, a significantly lower age at onset was detected for carriers of $A P O E \varepsilon 4$.

To control for the effect of age, $A P O E$ allele frequencies were also examined with respect to onset of disease in three separate age groups for the patients, and compared with age at inclusion for control individuals, as shown in table 6. The youngest age

Table 4 OR for developing DLB or $A D$ relative to $A P O E \varepsilon 2$ and $A P O E \varepsilon 4$ alleles adjusted for age and gender

\begin{tabular}{llc}
\hline & DLB vs CTR & AD vs CTR \\
\hline $\begin{array}{l}\text { No. of } A P O E \text { alleles } \\
1 \text { or } 2 \text { APOE \&2 alleles }\end{array}$ & \\
OR & 0.4 & 0.5 \\
Cl & 0.3 to 0.8 & 0.4 to 0.8 \\
p Value & 0.004 & $<0.0005$ \\
1 APOE \&4 allele & & \\
OR & 2.9 & 4.2 \\
Cl & 2.2 to 4.6 & 3.2 to 5.4 \\
p Value & $<0.0005$ & $<0.0005$ \\
2 APOE \&4 alleles & & \\
OR & 5.9 & 15.2 \\
Cl & 2.7 to 13.0 & 8.5 to 27.2 \\
p Value & $<0.0005$ & $<0.0005$ \\
\hline AD, Alzheimer's disease; CTR, healthy controls; DLM, dementia with Lewy bodies.
\end{tabular}


Table 5 The effect of $A P O E \varepsilon 2$ and $A P O E \varepsilon 4$ alleles on $A A O$ of DLB and $A D$

\begin{tabular}{|c|c|c|c|c|c|}
\hline & \multicolumn{2}{|l|}{0} & \multicolumn{2}{|l|}{1 or 2} & \multirow{2}{*}{$\begin{array}{l}\text { p Value, } \\
\text { Mann-Whitney U test }\end{array}$} \\
\hline & AAO & n & $\mathrm{AAO}$ & n & \\
\hline \multicolumn{6}{|c|}{ Number of $A P O E \varepsilon 2$ alleles } \\
\hline DLB & $71.9 \pm 7.7$ & 141 & $76.1 \pm 8.6$ & 15 & 0.01 \\
\hline$A D$ & $71.0 \pm 9.1$ & 460 & $73.9 \pm 10.5$ & 59 & 0.006 \\
\hline \multicolumn{6}{|c|}{ Number of $A P O E \varepsilon 4$ alleles } \\
\hline DLB & $73.1 \pm 8.3$ & 72 & $71.5 \pm 7.5$ & 84 & 0.08 \\
\hline$A D$ & $73.6 \pm 10.0$ & 174 & $70.1 \pm 8.7$ & 345 & $<0.0005$ \\
\hline
\end{tabular}

group included the individuals aged 65 or less, corresponding to young-onset dementia. In this subset, a significant increase in the frequency of the APOE $\varepsilon 4$ allele was found between the AD and control groups $\left(\mathrm{p}<0.0005\right.$, Pearson's $\chi^{2}$ test), and between the patients with DLB and the controls $\left(p=0.03\right.$, Pearson's $\chi^{2}$ test). No other significant differences were found.

In the 66-79-year age group, which included most individuals, strongly significant increases in the frequency of the $A P O E \varepsilon 4$ allele were again found in patients with $\mathrm{AD}$ or DLB compared with the controls $\left(p<0.0005\right.$, Pearson's $\chi^{2}$ test), and the frequency was higher in AD compared with DLB $(\mathrm{p}=0.0001$, Pearson's $\chi^{2}$ test). The frequency of the APOE $\varepsilon 2$ allele was similar in both patient groups, with a significant reduction being observed relative to the controls (DLB: $p=0.006$; AD: $\mathrm{p}<0.0005$, Pearson's $\chi^{2}$ test). In the oldest group of participants (80 years and above), the only significant change found was an increase of the APOE $\varepsilon 4$ allele in patients with $\mathrm{AD}$ compared with the control group ( $p=0.003$, Pearson's $\chi^{2}$ test).

Allele frequencies in the three age categories were also compared within each study group. The greatest differences were found between the youngest and oldest individuals. Although no differences in the occurrence of the three $A P O E$ alleles were found at any age in the control group, the occurrence of the APOE $\varepsilon 2$ allele increased with age at onset in patients with $\mathrm{AD}(\mathrm{p}=0.014$, Pearson's $\chi^{2}$ test), whereas the APOE $\varepsilon 4$ allele decreased significantly with age at onset $\left(\mathrm{p}<0.0005\right.$, Pearson's $\chi^{2}$ test).

Table 6 APOE allele frequencies according to age (age at onset for patients and age at inclusion for healthy controls)

\begin{tabular}{|c|c|c|c|c|c|}
\hline & \multirow[b]{2}{*}{ Age (years) } & \multirow[b]{2}{*}{$n$} & \multicolumn{3}{|c|}{ Allele frequencies (\%) } \\
\hline & & & $\varepsilon 2$ & $\varepsilon 3$ & $\varepsilon 4$ \\
\hline \multirow[t]{3}{*}{ DLB } & $\leq 65$ & 30 & 3.3 & 60.0 & $36.7^{*}$ \\
\hline & $66-79$ & 100 & $4.0^{*}$ & 62.0 & $34.0^{*}$ \\
\hline & $\geq 80$ & 26 & 11.5 & 69.3 & 19.2 \\
\hline \multirow[t]{3}{*}{$A D$} & $\leq 65$ & 144 & 4.5 & 41.3 & $54.2^{*}$ \\
\hline & $66-79$ & 263 & $4.7^{*}$ & 50.8 & $44.5^{*}, \dagger$ \\
\hline & $\geq 80$ & 112 & $9.8 \ddagger$ & 65.6 & $24.6^{*}, \ddagger$ \\
\hline \multirow[t]{3}{*}{ Healthy controls } & $\leq 65$ & 59 & 10.2 & 72.0 & 17.8 \\
\hline & $66-79$ & 426 & 9.9 & 76.3 & 13.8 \\
\hline & $\geq 80$ & 158 & 12.7 & 72.7 & 14.6 \\
\hline
\end{tabular}

*Significant difference between a patient group and the control group. tSignificant difference between the groups of patients with DLB or AD.

$\ddagger$ Significant difference in allele frequency according to age within the respective group (Pearson's $\chi^{2}$ test).

AD, Alzheimer's disease; DLB, dementia with Lewy bodies.

\section{DISCUSSION}

The most important finding of the present data was the beneficial effect of the APOE $\varepsilon 2$ allele in reducing the risk of DLB, an effect that was maintained after correction for age and gender. In our material, the $A P O E \varepsilon 2$ allele reduced the risk for DLB, and delayed the onset of disease by around 4 years. It is well known that the $A P O E \& 2$ allele reduces the risk of $\mathrm{AD}^{9}$ and this was clearly found also in the present study.

Conversely, the APOE $\varepsilon 4$ allele increased the risk for disease in a dose-dependent manner, and reduced the age at onset of DLB and AD, which has been demonstrated in previous studies $^{22} 23$ including a recent large series of DLB patients. ${ }^{24}$ In our study, although the onset of $\mathrm{AD}$ was accelerated by around 3.5 years, the effect on the onset of DLB was less pronounced with an earlier start of around 1.6 years.

The beneficial effect of the APOE $\varepsilon 2$ allele on the risk for, and onset of, DLB may be particularly pronounced in this study as it has already been established that the APOE $\varepsilon 2$ allele has a high frequency in Norway ${ }^{5}$ compared with data from a wider meta-analysis. ${ }^{25}$ This infers that the difference might be less clear in populations of mixed ethnicity.

These results were also supported by data when control and patient groups were divided into three separate age groups. A significant reduction in the frequency of $A P O E \varepsilon 2$ was only observed for the 66-79 age group, whereas the frequency in the age group 80 years and over was similar to the level in the control group. Although not significant due to the low number of individuals in the group, the data tentatively suggest that the protective effect of $A P O E \varepsilon 2$ is lost by age 80 years, perhaps due to multiple comorbidities. ${ }^{26}$ Similarly among the oldest patients with $\mathrm{AD}$, no reduction in the frequency of $A P O E \varepsilon 2$ was found, complementing the data from patients with DLB. Similar results were observed with the APOE $\varepsilon 4$ allele, and support existing evidence ${ }^{27}$ that for patients who develop AD in more extreme old age, the APOE ع4 allele is less relevant as a risk factor, perhaps because most affected individuals have developed $\mathrm{AD}$ at an earlier age.

It is debatable how the $A P O E$ genotype affects dementia development. Considerable attention has been focused on the chaperone ability of ApoE to clear $\mathrm{A} \beta$ deposition in connection with AD. ${ }^{28} 29$ Several aspects suggest that APOE is important for the clearance of $\mathrm{A} \beta$, but the $A P O E \varepsilon 4$ genotype is least effective, and thus accelerates $\mathrm{A} \beta$ deposition into plaque. ${ }^{29}$ These data are further supported by recent findings that anti-APOE immunotherapy inhibits $\mathrm{A} \beta$ deposition in a transgenic mouse model. ${ }^{30}$

Although the hallmark of DLB is Lewy body pathology with lesions rich in $\alpha$-synuclein, several clinical and neuropathological features of $\mathrm{DLB}$ overlap with $\mathrm{AD}$, including senile plaque and neurofibrillary tangles. However, these latter features are much more sparse in DLB, ${ }^{31}$ though the APOE $\varepsilon 4$ allele may accelerate this process in connection with disease. Since the APOE $\varepsilon 2$ genotype is much less common than APOE $\varepsilon 4$, fewer studies have been carried out on the mechanism behind its protection in $\mathrm{AD}$. The APOE $\varepsilon 2$ genotype may remove $\mathrm{A} \beta$ accumulation more efficiently, a hypothesis that has received some support, ${ }^{32}$ but in the absence of more data, this possibility, as well as other possible mechanisms, remains speculative. Recent data supports the parallels between DLB and AD. ${ }^{33}$

A limitation of the present study is the absence of neuropathological confirmation of the diagnosis for the majority of cases, and we lack data in vivo on the extent of brain load of deposited $A \beta$, so we cannot distinguish between pure and mixed DLB cases. However, results from a recent study supported by 
neuropathology ${ }^{34}$ show an increased risk for pure DLB due to the APOE $\varepsilon 4$ allele that is similar to the present results. This suggests that our results concerning the APOE $\varepsilon 2$ allele are also likely to be reliable. DLB patients were drawn from two cohorts, with slightly different selection and diagnostic procedures. However, demographic factors such as age, gender, and education were similar suggesting that the groups are comparable, as was supported by the similar genotype distribution.

Our results also agree with recent data ${ }^{24}$ demonstrating that many risk factors for $\mathrm{AD}$, including the $\mathrm{APOE} \varepsilon 4$ allele, are also risk factors for DLB. Such similarities may extend to the $A P O E$ $\varepsilon 2$ allele, long recognised as a protective factor in $\mathrm{AD},{ }^{69}$ and apparently also a protective factor reducing the risk, and raising the average age at onset of DLB.

Acknowledgements The authors are grateful to the patients and their caregivers, as well as the healthy individuals, for participating in this study.

Contributors Design and conduct of the study: SBS, LRW, DAa and AR; Collection of data: SBS, DAa, AR and GB; Management, analysis and interpretation of the data: all authors; Statistical analysis: LRW and GB; Drafting of the manuscript: LRW and $\mathrm{GB}$; Critical revision of the manuscript for important intellectual content: all authors; Obtained funding: LRW.

Funding GB holds a PhD scholarship (46060903) from the Liaison Committee between the Central Norway Health Authority and NTNU. This study is part of a cross-regional collaboration, Dementia Disease Initiation (DDI), and is supported by grants from the Research Council of Norway (NASATS-NevroNor grant 217780/H10), South-Eastern Regional health Authority, Western Regional health Authority, Central Regional health Authority and Northern Norway Regional health Authority. The project is approved by The National Committees for Research Ethics (Approval 2013/150).

Ethics approval Regional Committee for Medical Research Ethics.

Provenance and peer review Not commissioned; externally peer reviewed.

Open Access This is an Open Access article distributed in accordance with the Creative Commons Attribution Non Commercial (CC BY-NC 3.0) license, which permits others to distribute, remix, adapt, build upon this work non-commercially, and license their derivative works on different terms, provided the original work is properly cited and the use is non-commercial. See: http://creativecommons.org/ licenses/by-nc/3.0/

\section{REFERENCES}

1 Hardy J, Gwinn-Hardy K. Neurodegenerative disease: a different view of diagnosis. Mol Med Today 1999;5:514-17.

2 Armstrong RA, Lantos PL, Cairns NJ. Overlap between neurodegenerative disorders. Neuropathology 2005;25:111-24.

3 Baxter LC, Caselli RJ, Johnson SC, et al. Apolipoprotein E $\varepsilon 4$ affects new learning in cognitively normal individuals at risk for Alzheimer's disease. Neurobiol Aging 2003;24:947-52.

4 Van der Flier WM, Pijnenburg YAL, Schoonenboom NM, et al. Distribution of APOE genotypes in a memory clinic cohort. Dement Geriatr Cogn Disord 2008;25:433-8.

5 Sando SB, Melquist S, Cannon A, et al. APOE \&4 lowers age at onset and is a high risk factor for Alzheimer's disease; a case control study from central Norway. BMC Neurol 2008:8:9

6 Liu Y, Paajanen T, Westman E, et al. APOE \&2 allele is associated with larger regional cortical thicknesses and volumes. Dement Geriatr Cogn Disord 2010;30:229-37.

7 Engelborghs S, Dermaut B, Goeman J, et al. Prospective Belgian study of neurodegenerative and vascular dementia: APOE genotype effects. J. Neurol Neurosurg Psychiatry 2003;74:1148-51.

8 Corder EH, Saunders AM, Risch NJ, et al. Protective effect of apolipoprotein $\mathrm{E}$ type-2 allele for late-onset Alzheimer's disease. Nat Genet 1994;7:180-4.

9 Talbot $\mathrm{C}$, Lendon $\mathrm{C}$, Craddock N, et al. Protection against Alzheimer's disease with APOE ع2. Lancet 1994:343:1432-33.
10 McKeith IG, Dickson DW, Lowe J, et al. Diagnosis and management of dementia with Lewy bodies: third report of the DLB consortium. Neurology 2005:65:1863-72.

11 Meeus B, Theuns J, Van Broeckhoven C. The genetics of dementia with Lewy bodies. What are we missing? Arch Neurol 2012;69:1113-18.

12 Neef D, Walling AD. Dementia with Lewy bodies: an emerging disease. Am Fam Physician 2006;73:1223-29.

13 Singleton $A B$, Wharton $A, O^{\prime} B$ rien $K K$, et al. Clinical and neuropathological correlates of apolipoprotein $\mathrm{E}$ genotype in dementia with Lewy bodies. Dement Geriatr Cogn Disord 2002;14:167-75.

14 Kobayashi S, Tateno M, Park TW, et al. Apolipoprotein E4 frequencies in a Japanese population with Alzheimer's disease and dementia with Lewy bodies. Plos ONE 2011;6:e18569.

15 Lane $\mathrm{R}$, He YS, Morris $\mathrm{C}$, et al. BuChE-K and APOE $\varepsilon 4$ allele frequencies in Lewy body dementias, and influence of genotype and hyperhomocysteinemia on cognitive decline. Mov Disord 2009;24:392-400.

16 Tsuang DW, Dalan AM, Eugenio CJ, et al. Familial dementia with Lewy bodies: a clinical and neuropathological study of 2 families. Arch Neurol 2002:59:1622-30.

17 McKhann G, Drachman D, Folstein M, et al. Clinical diagnosis of Alzheimer's disease Report of the NINCDS-ADRDA work group under the auspices of Department of Health and Human Services Task force on Alzheimer's Disease. Neurology 1984;34:939-44.

18 McKeith IG, Galasko D, Kosaka K, et al. Consensus quidelines for the clinical and pathologic diagnosis of dementia with Lewy bodies (DLB): Report of the consortium on DLB international workshop. Neurology 1996:47:1113-24.

19 Aarsland D, Rongve A, Nore SP, et al. Frequency and case identification of dementia with Lewy bodies using the revised consensus criteria. Dement Geriatr Cogn Disord 2008;26:445-52.

20 Launer $\mathrm{L}$, Andersen K, Dewey ME, et al. Rates and risk factors for dementia and Alzheimer's disease: results from EURODEM pooled analyses. EURODEM Incidence Research Group and Work Groups. European Studies of Dementia. Neurology 1999:52:78-84.

21 Siepel FJ, Rongve A, Buter TC, et al. $\left({ }^{123}\right.$ ) )FP-CIT SPECT in suspected dementia with Lewy bodies: a longitudinal case study. BMJ Open 2013;3:pii: e002642.

22 Kurz A, Altland K, Lautenschlager N, et al. Apolipoprotein E type 4 allele and Alzheimer's disease: effect on age at onset and relative risk in different age groups. J Neurol 1996;243:452-6.

23 Hardy J, Crook R, Prihar G, et al. Senile dementia of the Lewy body type has an apolipoprotein $\mathrm{E} \varepsilon 4$ allele frequency intermediate between controls and Alzheimer's disease. Neurosci Lett 1994;182:1-2.

24 Boot BP, Orr CF, Ahlskog JE, et al. Risk factors for dementia with Lewy bodies. Neurology 2013;81:833-40.

25 Farrer LA, Cupples LA, Haines $\mathrm{JL}$, et al. Effects of age, sex, and ethnicity on the association between apolipoprotein $\mathrm{E}$ genotype and Alzheimer disease. A meta-analysis. JAMA 1997:278:1349-56.

26 Brumback-Peltz C, Balasubramanian AB, Corrada MM, et al. Diagnosing dementia in the oldest-old. Maturitas 2011;70:164-8.

27 Corrada MM, Paganini-Hill A, Berlau DJ, et al. Apolipoprotein E genotype, dementia, and mortality in the oldest old: the 90+ Study. Alzheimers Demen 2013:9:12-8.

28 Hawkes CA, Sullivan PM, Hands $S$, et al. Disruption of arterial perivascular drainage of amyloid- $\beta$ from the brains of mice expressing the human APOE $\varepsilon 4$ allele. PLoS ONE 2012;7:e41636.

29 Kim J, Basak JM, Holtzman DM. The role of apolipoprotein E in Alzheimer's disease. Neuron 2009;63:287-303.

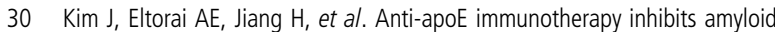
accumulation in a transgenic mouse model of $A \beta$ amyloidosis. J Exp Med 2012;209:2149-56.

31 Tsuboi Y, Dickson DW. Dementia with Lewy bodies and Parkinson's disease with dementia: are they different? Parkinsonism Relat Disord 2005;11(Suppl 1):S47-51.

32 Tokuda T, Calero M, Matsubara E, et al. Lipidation of apolipoprotein E influences its isoform-specific interaction with Alzheimer's amyloid $\beta$ peptides. Biochem J 2000;348(Pt 2):359-65.

33 Vijayaraghavan S, Maetzler W, Reimold M, et al. High apolipoprotein E in cerebrospinal fluid of patients with Lewy body disorders is associated with dementia. Alzheimers Dement 2013; in press.

34 Tsuang $\mathrm{D}$, Leverenz $\mathrm{JB}$, Lopez $\mathrm{OL}$, et al. APOE $\varepsilon 4$ increases risk for dementia in pure synucleinopathies. JAMA Neurol 2013;70:223-8. 